\title{
Virtual Reality as a Tool for Student Orientation in Distance Education Programs
}

\author{
A Study of New Library and Information Science Students \\ Sandra Valenti, Brady Lund, and Ting Wang
}

\begin{abstract}
Virtual reality (VR) has emerged as a popular technology for gaming and learning, with its uses for teaching presently being investigated in a variety of educational settings. However, one area where the effect of this technology on students has not been examined in detail is as tool for new student orientation in colleges and universities. This study investigates this effect using an experimental methodology and the population of new master of library science (MLS) students entering a library and information science (LIS) program. The results indicate that students who received a VR orientation expressed more optimistic views about the technology, saw greater improvement in scores on an assessment of knowledge about their program and chosen profession, and saw a small decrease in program anxiety compared to those who received the same information as standard textand-links. The majority of students also indicated a willingness to use VR technology for learning for long periods of time (25 minutes or more). The researchers concluded that VR may be a useful tool for increasing student engagement, as described by Game Engagement Theory.
\end{abstract}

\section{LITERATURE REVIEW}

Computer-assisted instruction (CAI) has, for many years, been considered an effective method of instructional delivery that improves student engagement and outcomes. ${ }^{1} \mathrm{New}$ technologies, such as the learning management system (LMS), online video, laptops and tablets, word processors, spreadsheets, and presentation platforms, have all significantly altered how knowledge is transferred and measured in students. When adopted by instructors, these technologies can improve the quality of student learning, work, and their evaluation of this work. Empirical research has shown that learning technologies do indeed contribute to better learning than a lecture alone. ${ }^{2}$ Positive reaction to the adoption of new learning technologies among student populations has been shown across all grade levels, from pre-K through postgraduate education. ${ }^{3}$

Research in the fields of instructional design technology (IDT) and information science (IS) have shown that the novelty of new learning technology provides short-term improvement in outcomes. ${ }^{4}$ This supports the broader hypothesis that engagement increases retention of knowledge. These findings would suggest that, at least in the short term, instructors could anticipate improvement in knowledge retention through the use of a new technology like virtual

Dr. Sandra Valenti (svalenti@emporia.edu) is Assistant Professor, School of Library and Information Management, Emporia State University. Brady Lund (blund2@g.emporia.edu) is doctoral student of Library and Information Management at Emporia State University. Ting Wang (twang2@emporia.edu) is doctoral student of Library and Information Management, Emporia State University. 
reality. When used in sustained instructional efforts, many learning technologies show some promise for improving the attainment of learning outcomes. ${ }^{5}$ This is why interest in learning technology has grown so significantly in the past two decades and the job outlook for instructional designers is increasing faster than the national average. ${ }^{6}$

A large proportion of instructional technologies are not truly "adopted" by instructors, but rather used only in one-off sessions and then discarded. ${ }^{7}$ There seem to be some common factors among those technologies that are adopted and used regularly by instructors:

1. Practicality, or the amount of work the new technology requires versus the perceived value of said technology;

2. Affordability, or the cost of a new technology versus the perceived value of said technology; and

3. Stability, or the likelihood of the product to be continuously supported and updated by its manufacturer (e.g., a product like Microsoft Office has a higher likelihood of ongoing maintenance). ${ }^{8}$

As noted by Lund and Scribner, only recently, with the introduction of free VR development programs and inexpensive viewers/headsets like Google Cardboard, has VR fit this criteria. ${ }^{9}$ It is finally practical to use VR as a learning tool for classrooms with large numbers of students.

"Virtual reality is the computer-created counterpart to actual reality. Through a video headset, computer programs present a visual world that can, pixel-perfectly, replicate the real world-or show a completely unreal one." ${ }^{10}$ Virtual reality is distinct from augmented reality, which augments a real-world, real-time image (e.g., viewed through a camera on a mobile device) with computer-generated information, such as images, text, videos, animation, and sound. ${ }^{11}$ The focus of the present study is virtual reality only, not related augmented (or mixed) reality technology.

An important contribution to the study of virtual reality in library and information science (LIS) is Varnum's Beyond Reality. ${ }^{12}$ This short introductory book covers both theoretical and practical considerations for the use of virtual, augmented, and mixed reality in a variety of library contexts. While the book describes how VR can be utilized in a variety of library education (for non-LIS majors) contexts, it does not include an example of how virtual reality may be used for library school education. It also does not investigate in significant detail the use of virtual reality for a virtual orientation to an academic program. These are the gaps in which the following study attempts to address.

The present study may be viewed through the framework game engagement theory, as described by Whitton. ${ }^{13}$ Game engagement theory suggests that five major learning engagement factors exist and that using gaming activities may improve how well learning activities address these factors. These factors include:

- challenge, motivation to undertake activity; control, the level of choice;

- immersion, extent to which an individual is absorbed into activity;

- interest, an individual's interest in the subject matter; and

- purpose, the perceived value of the outcome of the activity. 
It has been suggested by several researchers, including Dede, that immersive experiences like VR touch on similar factors of engagement. ${ }^{14}$

\section{EMPORIA STATE UNIVERSITY'S SCHOOL OF LIBRARY AND INFORMATION MANAGEMENT}

The setting for this study is Emporia (KS) State University's School of Library and Information Management (ESU SLIM). ESU SLIM is the oldest library school west of the Mississippi River, founded in 1902. Compared to other LIS education programs, ESU SLIM is unique in that it offers a hybrid course delivery format. The six core courses in the MLIS degree program are online with two in-person-class weekends for each class. Each class weekend is eleven hours: from 6 to 9 p.m. Friday and 9 a.m. to 5 p.m. Saturday at one of nine distance education locations scattered throughout the western half of the United States. Due to this course delivery format, the student population of ESU SLIM may skew slightly older and have more individuals who are employed fulltime in relation to residential master's programs. ESU SLIM uses a cohort system, with a new group of students beginning annually at each of the eight distance locations as well as the main Emporia, Kansas campus. Before each new cohort begins its first course, a one-day, in-person student orientation is offered on the campus in which the cohort will attend classes. The purpose of this experimental study is to examine how well VR technology can support or satisfy the role of the in-person student orientation by emulating the experience/information students receive during this informational session.

\section{METHODS}

This study was designed with a pre-test/post-test experimental design. Depending on the state in which the students reside, they were assigned either to the experimental or control group. The experimental group received a cardboard VR headset (similar to Google Cardboard) and a set of instructions on how to use them. They were instructed to utilize this headset to view an interactive experience that introduced elements of library service and library education as a form of new student orientation. Students in the control group received a set of links that contained the same information as the VR experience, but in a more static (non-immersive or interactive) setting.

Participants for this study were library school students from four states: South Dakota, Idaho, Nevada, and Oregon. These students were all enrolled in a mixed-delivery program in LIS. For each core course in the program, students attend two intensive, in-person, weekend class sessions. The rest of the course content is delivered via a learning management system. For this study, the researchers were particularly interested in understanding the role of VR orientation for distance education students, as these students do not have access to the physical university campus and thus miss out on information that in-person interaction with faculty and the library environment might provide. This also seemed like a worthwhile population to study given that a large portion of LIS programs have adopted the distance education (online or mixed-delivery) format.

In March 2019, a sample of this population was asked to complete a short survey to indicate their interest in virtual reality for new student orientation and the extent to which acquiring information via this medium may relieve their anxiety and increase their success in the program. Sixty-one percent of students indicated at least some elevated level of anxiety about their first MLS 
course, while 55 percent agreed that knowing more about the program's faculty and course structure and purpose would decrease that anxiety. Students were also asked to indicate the most pressing information needs they have about the program. These needs are displayed in table 1 below. This information was used to guide the design of the VR content for this study.

Table 1. Information needs expressed by new MLS students

\begin{tabular}{|l|l|}
\hline Information Need & $\begin{array}{l}\text { Number of } \\
\text { Respondents } \\
\text { (out of 55) }\end{array}$ \\
\hline Information about ESU's curriculum & 50 \\
\hline What courses professors normally teach & 42 \\
\hline Information about information access & 41 \\
\hline Information about librarianship in general & 39 \\
\hline Professors' research interests & 35 \\
\hline Information about ESU's faculty & 27 \\
\hline To see who they are via a video introduction & 25 \\
\hline Information about ESU's library & 24 \\
\hline Why they teach for ESU's MLS program & 23 \\
\hline A little personal information about faculty & 20 \\
\hline Information about my regional director & 14 \\
\hline To which associations do faculty belong & 13 \\
\hline Information about ESU's physical spaces & 5 \\
\hline Information about ESU's archives & 4 \\
\hline
\end{tabular}

These students were also asked to indicate the extent to which they would like to use VR to virtually "meet" faculty, learn more about the program's format, see program spaces, and learn about library services, using a five-point Likert scale. The findings for this question are displayed in figure 1. 


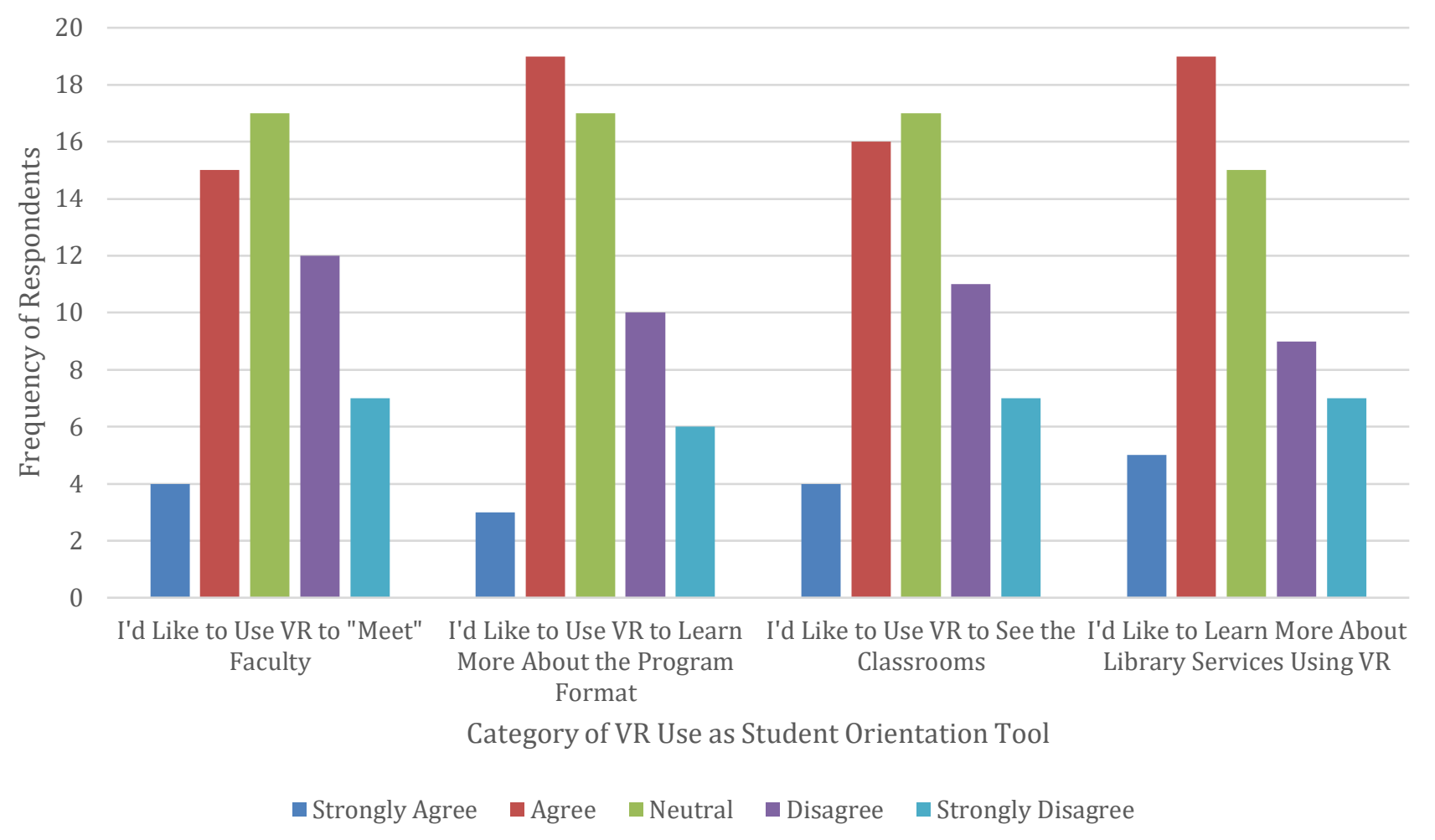

Figure 1. New MLS Students Reception to Using VR as an Orientation Tool

Based on the largely positive response towards using VR for new student orientation, the researchers progressed to the experimental phase of the study. A VR experience was developed using Veer VR (veer.tv), a completely free and intuitive VR-creation platform. Within this platform, creators are able to upload images that were captured using a 360-degree VR camera (we used a Samsung Gear 360 camera) and drag-and-drop interactive elements, including text boxes, videos, audio, and transitions to new images. Thus, it was possible to create a VR experience within the setting of an academic library where users could navigate throughout the building and virtually meet faculty and learn about fundamental concepts in librarianship.

For this phase of the study a set of research questions were defined, hypothesis created, and independent and dependent variables identified:

\section{Research Questions}

1. Research Question 1: Will VR improve students' knowledge of topics related to their library school and basic library topics, relative to those without a VR experience?

2. Research Question 2: Will VR reduce students' anxiety about their library program, relative to those without a VR experience?

3. Research Question 3: Will students' perceptions towards the usefulness of VR be significantly different based on whether or not they utilized the VR experience? 


\section{Hypothesis}

Use of VR will improve students' knowledge of topics related to library schools and librarianship, reduce their anxiety, and result in a more positive perspective towards VR technology.

\section{Variables}

Independent variable: Whether a student viewed the VR experience for a virtual orientation or viewed the web links for an online orientation.

Dependent variables: Change in students' scores on a post-test assessment of orientation knowledge, compared to their pre-test scores. Change in students' anxiety levels and perceptions of VR.

\section{EXPERIMENTAL PHASE}

The experimental phase of the study was conducted in August 2019. Twenty-nine students agreed to participate in this study. The age and gender characteristics of this population are as follows: fourteen under age 35, eleven age 35-44, four age 45+; nine male, seventeen female, and three fluid or transgender. Thirty-three percent of the students who agreed to participate were in the control group, while 67 percent were in the experimental group.

All participants in the study received a free VR headset, which was theirs to keep. Funding for these VR headsets was provided by a generous grant from a benefactor at the researchers' university. Participants in the control group were encouraged to use the VR headset after they had completed their participation in the study. Both groups received instructions with their viewer that instructed them to complete a pre-test survey, embedded within a module of their learning management system account. Following the pre-test, the experimental group was instructed to use the VR experience created by the researchers to learn about their library school, its faculty, and the library concepts. The control group was instructed to use links provided in the module to experience the same content, but without the VR experience. Following the experience, both groups were instructed to complete a post-test survey in the module, as well as a follow-up survey that asked questions about how long they interacted with the content, how the experience affected their program anxiety, and additional comments.

Once the data was collected for all participants, the researchers' conducted a series of analyses on the data, including an analysis of covariance (ANCOVA) for post-test scores among the control and experimental groups, and ANCOVA for program anxiety following the experimental treatment. ${ }^{15}$

\section{RESULTS}

Figure 2 displays the amount of time participants in the experimental group spent using the VR experience. Nearly 60 percent of participants spent more than 25 minutes using the virtual reality experience. This finding may seem remarkable, given the average attention span of students is generally no more than a handful of minutes, but aligns with that of Geri, Winer, and Zaks, who found that engagement with interactive video lengthens the attention span of users, and supports the premise of engagement theory as discussed in the literature review. ${ }^{16}$ Only 10 percent of individuals assigned to the experimental group decided not to use the headset. Additionally, about 
one-third of participants in both the experimental and control groups indicated that they used the VR headset to view other content after they completed the study.

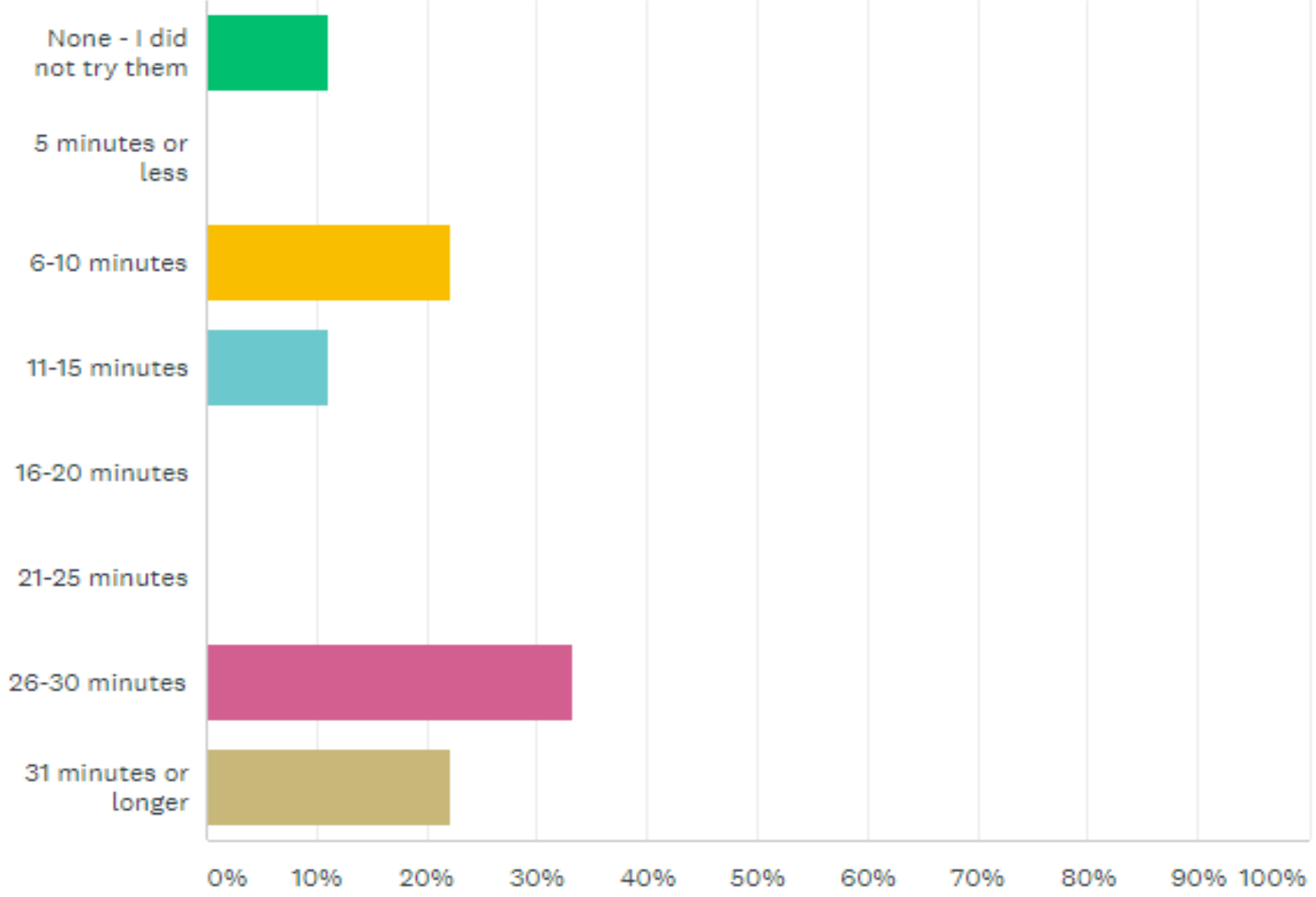

Figure 2. Amount of Time Experimental Group Participants Spent in VR Experience

In table 2, responses for Likert question about the participants' post-test perspectives of VR are shown. Participants in the VR group generally had more favorable perspectives on their experience than participants in the control group. Participants in the control group, however, were a bit more optimistic on the idea that VR has promising uses for education and librarianship (though both groups expressed optimistic perspectives on these questions). There was some indication that participants would be willing to use VR for student orientation again, as both groups responded favorably to the idea that VR orientation information is appropriate and negatively to the idea that it would be better to get information from other sources.

Tables 3 and 4 display the ANCOVA for pre-test/post-test score change among groups and the change in anxiety among the groups, respectively. Post-test scores for the experimental (17.23 correct out of 20 questions, or 86 percent) and control group (17.38/20, or 87 percent) were virtually identical; however the pre-test scores differed (experimental group, 72 percent, scored worse on the pre-test than control group, 78 percent), so the change in scores was actually greater for the experimental group. As shown in table 3, though, this difference in score change was not found to be statistically significant, $F(1,20)=.641 \mathrm{p}=.4, \mathrm{r}=.01$. That is, no significant difference was found as to whether VR improves scores compared to links. It can be concluded, however, that 
the links and VR together did improve scores from the pre-test to the post-test, with ANCOVA values of $F(1,20)=7.6, p<.01, r=.47$.

Table 2. Post-test Perspectives of VR for Experimental and Control Groups

\begin{tabular}{|l|c|c|}
\hline Question & $\begin{array}{l}\text { Control (text- } \\
\text { links)* }\end{array}$ & $\begin{array}{l}\text { Experimental } \\
\text { (VR)* }\end{array}$ \\
\hline $\begin{array}{l}\text { The instructions were easy to understand } \\
\text { and follow }\end{array}$ & 3 & 3.38 \\
\hline The viewer/text-links were fun to use & 3 & 3.63 \\
\hline The VR/text-links content was engaging & 2.67 & 3.13 \\
\hline $\begin{array}{l}\text { I would recommend continuing VR/text- } \\
\text { links use }\end{array}$ & 2.5 & 3.11 \\
\hline $\begin{array}{l}\text { I felt better informed about the topics } \\
\text { presented }\end{array}$ & 2.5 & 3.38 \\
\hline The information given was helpful & 2.5 & 2.88 \\
\hline $\begin{array}{l}\text { I feel more connected to the school than } \\
\text { before }\end{array}$ & 2 & 2.88 \\
\hline Virtual reality is just a fad & 4 & 3.5 \\
\hline There are exciting uses for VR in education & 4 & 3.5 \\
\hline $\begin{array}{l}\text { There are exciting uses for VR in } \\
\text { librarianship }\end{array}$ & 2.5 & 2.89 \\
\hline Using VR is too time consuming & 4 & 3.38 \\
\hline $\begin{array}{l}\text { I'd rather get information in formats other } \\
\text { than VR }\end{array}$ & & \\
\hline VR orientation information is appropriate & & \\
\hline
\end{tabular}

*Five-point Likert Scale (level of agreement-1, strongly disagree; 5, strongly agree)

Table 3. ANCOVA for Pre-test/Post-test Change in Scores

\begin{tabular}{|l|l|l|l|}
\hline & $\begin{array}{l}\text { Degrees of } \\
\text { Freedom }\end{array}$ & $\begin{array}{l}\text { F- } \\
\text { value }\end{array}$ & $\begin{array}{l}\text { p- } \\
\text { value }\end{array}$ \\
\hline Pretest & 1 & .135 & .7 \\
\hline Group & 1 & .641 & .4 \\
\hline Error & 18 & & \\
\hline Total & 19 & & \\
\hline $\begin{array}{l}\text { Corrected } \\
\text { Total }\end{array}$ & 20 & & \\
\hline
\end{tabular}

Though the VR group generally reported less anxiety on a five-point Likert scale following the experiment than the control group (both groups showed some reduction), this difference was not statistically significant at $\mathrm{p}<.05$ (though it was significant at $\mathrm{p}<.1$ ). It is worth noting that few students indicated prior experience with VR before this study, so it may have simply been the unfamiliar technology that resulted in anxiety not dropping as far as anticipated, not the nature of the content. At the same time, it is worth noting, as Bawden and Robinson did, that information overload, which could certainly be the product of immersive VR orientations, is connected to 
information anxiety. ${ }^{17}$ Thus, it may be better, in the design of VR orientations, to keep the amount of new information at a minimum, only introducing broad concepts and allowing more freedom and flexibility for the user.

Table 4. ANCOVA for Anxiety Following the Orientation Experience

\begin{tabular}{|l|c|c|c|c|c|}
\hline & Sum of Squares & df & Mean Square & $\mathbf{F}$ & Sig. \\
\hline Between Groups & 3.219 & 1 & 3.219 & $\begin{array}{c}3.44 \\
9\end{array}$ & $\begin{array}{c}.07 \\
9\end{array}$ \\
\hline Within Groups & 17.733 & 19 & .933 & & \\
\hline Total & 20.952 & 20 & & & \\
\hline
\end{tabular}

\section{DISCUSSION}

Participants in this study expressed willingness to use VR for extended periods of time (over 25 minutes) and demonstrated strong levels of engagement. Based on this finding, it seems possible that a well-designed VR orientation could be a suitable substitute for the in-person orientation for distance students. This is a significant finding, given that the majority of existing research on orientation for distance education students focuses on the design of online course modules or video streaming for orientation, which are not nearly as immersive and dynamic as physical presence in the environment. ${ }^{18}$ VR much more closely emulates physical presence than noninteractive/immersive videos and text.

Those among the participants who were in the experimental (VR) group expressed more favorable perspectives towards the technology. This suggests that experience with the technology increases comfort and interest in the technology. This aligns with the findings of Theung, Mei-Ling, Liu, Cheok, among others, who found that use of VR were more likely to accept the technology after usage. ${ }^{19}$ Additionally, stated interest in using VR for other purposes, including one-third of participants who have already utilized the technology to explore other apps suggested by the researchers.

The findings of this study align with game engagement theory in several of its key aspects. VR is shown to have garnered the interest of the students who participated in the study, as indicated in table 2, aligning with the aspect of interest. They could see the purpose of the experience and were able to take control of the experience to ensure that they interacted with necessary information to satisfy this purpose. This is opposed to the control group, which had to follow links and read text in a sequential order with little control or creativity involved. Accordingly, greater improvement in scores was observed for the experimental group. Even though the improvement was not statistically significant, this could likely be explained by the relatively small sample size. With a larger number of participants, the statistical strength of the differences between the two study groups may have been more pronounced. This is one limitation of the present study.

In addition to a small participant group, several other limitations exist with this study. Participants came from only a small sample of states, all in the western half of the United States. A less homogeneous sample may have produced more robust results. Some VR headsets arrived late due to delays in distributing them, giving the students less opportunity to review the content than 
they otherwise may have had. Finally, the researchers were not able to easily troubleshoot problems with accessing the VR experience for distance students. While the best was done to help all participants figure out how to use the technology, several students opted to discontinue participation when the technology gave them trouble. This also led to a smaller study sample population than initially anticipated.

\section{CONCLUSION}

The findings of this study may have several important implications for library professionals who are considering using VR technology for library orientations or instruction. This study found VR to have a positive effect on students' interest and to slightly increase scores and reduce anxiety among them. While there is no indication from this study whether VR would produce positive effects over a sustained period of time (e.g., every class session over the course of a semester), in limited usage it appears to at least draw students' attention more so than the traditional online teaching options like static text and links. The same VR experience developed to introduce students to basic concepts within the librarianship/the library could be used for undergraduate and graduate students in all majors during library orientation sessions. This may make the library a more memorable component of students' early university experiences, as opposed to lecture information that students are likely to easily forget. Library professionals may consider these factors when deciding whether to opt for the more traditional methods of instruction/orientation or experimenting with a more innovative method of teaching like virtual reality.

\section{ENDNOTES}

${ }^{1}$ Jennifer J. Vogel et al., "Using Virtual Reality with and without Gaming Attributes for Academic Achievement," Journal of Research on Technology in Education 39, no. 1 (2006): 105-18, https://doi.org/10.1080/15391523.2006.10782475.

2 Yigal Rosen, "The Effects of an Animation-based On-line Learning Environment on Transfer of Knowledge and on Motivation for Science and Technology Learning," Journal of Educational Computing Research 40, no. 4 (2009): 451-67, https://doi.org/10.2190/EC.40.4.d; Elisha Chambers, Efficacy of Educational Technology in Elementary and Secondary Classrooms: A Metaanalysis of the Research Literature from 1992-2002 (Carbondale, IL: Southern Illinois University at Carbondale, 2002).

${ }^{3}$ Elisha Chambers, "Efficacy of Educational Technology in Elementary and Secondary Classrooms: A Meta-analysis of the Research Literature from 1992-2002," PhD diss., Southern Illinois University at Carbondale, 2002.

${ }^{4}$ Jason M. Harley et al., "Comparing Virtual and Location-based Augmented Reality Mobile Learning: Emotions and Learning Outcomes," Educational Technology Research and Development 64, no. 3 (2016): 359-88, https://doi.org/10.1007/s11423-015-9420-7; Jocelyn Parong and Richard E. Mayer. "Learning Science in Immersive Virtual Reality," Journal of Educational Psychology 110, no. 6 (2018): 785-95, https://doi.org/10.1037/edu0000241; Paul Legris, John Ingham, and Pierre Collerette, "Why Do People Use Information Technology? A 
Critical Review of the Technology Acceptance Model," Information and Management 40, no. 3 (2003): 191-204, https://doi.org/10.1016/S0378-7206(01)00143-4.

${ }^{5}$ Zaid Khot et al., "The Relative Effectiveness of Computer-based and Traditional Resources for Education in Anatomy," Anatomical Sciences Education 6, no. 4 (2013): 211-15, https://doi.org/10.1002/ase.1355; Michael J. Robertson and James G. Jones, "Exploring Academic Library Users' Preferences of Delivery Methods for Library Instruction," Reference \& User Services Quarterly 48, no. 3 (2011): 259-69.

6 Joshua Kim, "Instructional Designers by the Numbers," Inside Higher Ed (2015), https://www.insidehighered.com/blogs/technology-and-learning/instructional-designersnumbers.

${ }^{7}$ Elena Olmos-Raya et al., "Mobile Virtual Reality as an Educational Platform: A Pilot Study on the Impact of Immersion and Positive Emotion Induction in the Learning Process," Eurasia Journal of Mathematics Science and Technology Education 14, no. 6 (2018): 2045-57, https://doi.org/10.29333/ejmste/85874.

${ }^{8}$ Brady D. Lund and Shari Scribner, "Developing Virtual Reality Experiences for Archival Collections: Case Study of the May Massee Collection at Emporia State University," The American Archivist, https://doi.org/10.17723/aarc-82-02-07.

${ }^{9}$ Lund and Scribner, "Developing Virtual Reality Experiences for Archival Collections."

${ }^{10}$ Kenneth J. Varnum, “Preface," in Kenneth J. Varnum, ed., Beyond Reality: Augmented, Virtual, and Mixed Reality in the Library (Chicago: ALA Editions, 2019): $\mathrm{x}$.

${ }^{11}$ Brady D. Lund and Daniel A. Agbaji, "Augmented Reality for Browsing Physical Collections in Academic Libraries,” Public Services Quarterly 14, no. 3 (2018): 275-82, https://doi.org/10.1080/15228959.2018.1487812.

12 Kenneth J. Varnum, ed., Beyond Reality: Augmented, Virtual, and Mixed Reality in the Library (Chicago: ALA Editions, 2019).

${ }^{13}$ Nicola Whitton, "Game engagement theory and adult learning," Simulation and Gaming 42, no. 5 (2011): 596-609, https://doi.org/10.1177/1046878110378587.

${ }^{14}$ Chris Dede, "Immersive interfaces for engagement and learning," Science 323, no. 5910 (2010): 66-69, https://doi.org/10.1126/science.1167311.

15 Pat Dugard and John Todman, "Analysis of Pre-test-Post-test Control Group Designs in Educational Research,” Educational Psychology 15, no. 2 (1995): 181-98, https://doi.org/10.1080/0144341950150207. 
${ }^{16}$ Nitza Geri, Amir Winer, and Beni Zaks, "Challenging the Six-minute Myth of Online Video Lectures: Can Interactivity Expand the Attention Span of Learners?," Online Journal of Applied Knowledge Management 5, no. 1 (2017): 101-11.

${ }^{17}$ David Bawden and Lyn Robinson, "The Dark Side of Information: Overload, Anxiety and Other Paradoxes and Pathologies," Journal of Information Science 35, no. 2 (2009): 180-91, https://doi.org/10.1177/0165551508095781.

${ }^{18}$ Moon-Heum Cho, "Online Student Orientation in Higher Education: A Developmental Study," Educational Technology Research and Development 60, no. 6 (2012): 1051-69, https://doi.org/10.1007/s11423-012-9271-4; Karmen Crowther and Alan Wallace, "Delivering Video-streamed Library Orientation on the Web: Technology for the Educational Setting," College and Research Libraries News 62, no. 3 (2001): 280-85.

${ }^{19}$ Yin-Leng Theng et al., "Mixed Reality Systems for Learning: A Pilot Study Understanding User Perceptions and Acceptance," International Conference on Virtual Reality (2007): 728-37, https://doi.org/10.1007/978-3-540-73335-5_79. 